\title{
Dynamics of Contextual Factors, Technology Paradox, and Job Performance in Smartphone Usage:
}

\section{A Systematic Review}

\author{
Maria Alhadad, University Teknologi Malaysia, Malaysia* \\ Rosmini Omar, Universiti Teknologi Malaysia, Malaysia \& University of Business and Technology, Saudi Arabia \\ Mohamed Dashti, Kuwait University, Kuwait
}

\begin{abstract}
The purpose of this paper is to explore the theories pertaining to the dynamics of contextual factors, technology paradox, and job performance of employees so as to answer specific questions related to the theories' progressive advancement and to evaluate the relationships among them in the context of mobile phones using the evidence-based systematic review methodology. The term technology paradox has evolved over past decades, and theories have been postulated to explain its nature and relationships with its antecedents and outcomes; however, there is a dearth in the integrative models. Thus, the theory of paradox has been combined with other theoretical lenses to conceptualize tensions and responses to enrich extant theories on technology paradox and job performance. The finding of the study identifies seven research gaps in the available literature, which need to be plugged so that a holistic model is developed to address the interrelationships among the aforementioned research constructs.
\end{abstract}

\section{KEYWORDS}

Contextual Factors, Job Performance, Smartphones, Systematic Literature Review, Technology Acceptance Model, Technology Paradox, Theory of Reasoned Action

\section{INTRODUCTION}

Technology paradox has been an active area of research since the past decade, but its relationship with the performance of employees in the workplace is relatively underexplored. The word technology in the technology paradox refers to various technologies used in service and manufacturing industries in general, but the focus of this research is information and communication technologies (ICTs), mainly smartphones in the workplace, and their relationship with employees' job performance. A paradox is a widely spread phenomenon in organizations (Lewis \& Smith, 2014). In the context of technology, a paradox manifests when technology users recognize the opposing outcomes of technology use due to the conflict between their initial expectations of how technology is supposed to function and the actual performance of technology (Mazmanian, Orlikowski, \& Yates, 2013; Mick $\&$ Fournier, 1998). Contemporary workplaces are characterized by uncertainty and unpredictability that impact employees working within such ambiguous business environments (Cullen, Edwards, Casper, \& Gue, 2014), and technology, as a context, can act as a driving factor to the emergence of 
a technology paradox, which further provokes tensions and internal conflicts in employees that need to be addressed by workers as well as their organizations (Bruzzi \& Joia, 2015; Clegg, Cunha, \& Cunha, 2002). Therefore, technology as a context makes latent tensions more salient, thereby enabling researchers to easily identify them (Jarzabkowski, Lê, \& Van de Ven, 2013). However, traditional rational technology acceptance theories are insufficient for explaining the intuitive and automatic behavior of employees using smartphones for work-related purposes (Buettner, 2015), and there is a need for a thorough review of the underpinning theories in this area.

\section{BACKGROUND}

The notion of technology paradox has received attention in the literature from the work of Mick and Fournier (1998), who had undertaken the pioneering work specifically in the consumer's perspective and provided the basic model of technology paradox. Based on this model, Jarvenpaa and Lang (2005) identified eight technology paradoxes through semi-structured interviews; however, there were ambiguities between the dimensions that were to be clarified through further investigation. Ter Hoeven, van Zoonen, and Fonner (2016) studied the practical paradox of technology in communication technology use for work, which enables spatial and temporal flexibility, and found that communication technology use increases well-being through accessibility and efficiency, while at the same time, decreasing well-being through interruptions and unpredictability. This research relied on crosssectional data, so causation was not possible. Ratna and Kaur (2016) studied the impact of technology on job-related aspects and found that newer technologies had an impact on the performance of employees, but this research was based on convenience sampling, and its generalization remained questionable. Van Zoonen and Rice (2017) examined the paradoxical implications of personal social media use for work on employees' autonomy and work pressure and how those relationships are moderated by employees' sense of responsiveness to colleagues' social media use. The study concluded that employees were more likely to be stressed by the use of personal social media than to benefit from it. Therefore, there is a scope to extend this study using mobile applications of social media platforms, which differ in features and functionalities, as they provide more autonomy from a location-based computer and increase employees' responsiveness (Mazmanian et al., 2013). Schlachter, McDowall, Cropley, and Inceoglu (2018) focused on the empowerment-enslavement paradox in particular and found that it was the non-manual performance of employees that was affected by the technology paradox. In the backdrop of these studies, various theoretical models are discussed to answer the research questions that originated through the literature review.

\section{THEORIES OF TECHNOLOGY AND JOB PERFORMANCE}

Several theories have evolved over a period of time that deal with the dynamics of the technology paradox and job performance in the business environment. While this paper specifically focuses on mobile technology, these theories are generic and applicable to all forms of ICTs that are usable in the business environment. Further, in the research literature, contextual factors that act as the antecedents (Jarvenpaa \& Lang, 2005) and the technology paradox are dealt with concurrently as the technology paradox.

The theory of paradox is the basic theory that introduces the very concept of a paradox, according to which a paradox is "contradictory yet interrelated elements that exist simultaneously and persist over time" (Smith \& Lewis, 2011, p. 382). This definition emphasizes two fundamental elements: contradiction, which highlights conflicts between two distinct elements, and interdependence, which describes the co-existence, synergy, and interwoven nature of these contradictory elements (Andriopoulos \& Gotsi, 2017). Furthermore, the word paradox triggers a context-based meaning (Lewis, 2000), and some contexts are more likely to produce tensions than others (Jarzabkowski et al., 2013). In the context of technology, technology paradoxes manifest in a state, undertaking, 
or behavior that has inconsistent or contradictory qualities that are interdependent and co-occur to generate technology paradoxes (Jarvenpaa \& Lang, 2005) that are dynamic, constantly shifting between conflicting positive and negative aspects (Johnson, Bardhi, \& Dunn, 2008) due to situational or contextual factors (Mick \& Fournier, 1998). The literature on technology paradox proposes that contextual factors do have their impact in conflicting situations in the experience of technology users (Chae \& Yeum, 2010; Jarvenpaa \& Lang, 2005; Mick \& Fournier, 1998).

The theory of reasoned action (TRA) is about the attitude forming an intention, which is responsible for a behavior (Fishbein \& Ajzen, 1975; Hagger, 2019). From a paradoxical perspective, new ICTs can have ambiguous and contradictory consequences, as they may be redeeming and coercing at the same time (van Zoonen \& Rice, 2017). Smartphone users usually experience ambiguous and ambivalent feelings or emotions that arise from perceived disagreements between expectations formed due to beliefs and the external reality (Johnson et al., 2008), which leads to experiencing a technology paradox. A paradox is perceptual in that it develops out of individuals' responses to contradictory situations that are usually constructed cognitively and socially as paradoxes (Lewis \& Smith, 2014; Smith \& Tushman, 2005) and can be influenced by national culture (Smith, Erez, Jarvenpaa, Lewis, \& Tracey, 2017).

The theory underpinning the has widely been used, particularly in the context of mobile technology (Otieno, Liyala, Odongo, \& Abeka, 2016). Davis, Bagozzi, and Warshaw (1989) considered perceived usefulness and perceived ease of use to be the two primary determinants that would cultivate attitudes toward mobile technology use, which in turn determined actual system use, the basis for the TAM. Critics of the TAM mainly argue that it completely ignores sociological and organizational aspects in addressing the adoption of newer technologies (Otieno et al., 2016). Maulani and Hamdani (2019), having considered the relevance of this model, applied it specifically to the study of mobile technology acceptance by the end-user and considered situational factors and past technology experience to be the dominant factors that comprise behavioral intentions for use.

The technology, organization, and environment (TOE) framework (Tornatzky, Fleischer \& Chakrabarti, 1990) provides a basis for understanding how innovation becomes diffused in a society. The framework provides three distinct aspects that govern the process controlling the adoption of new technology — namely, technological context, organizational context, and environmental context. The TOE framework was adopted in the cloud computing environment, and it was observed that the three contexts referred to in the model exemplified new technology adoption (Micheni, 2015). The TOE framework has also provided empirical evidence for the relationships between its antecedents and technology adoption in the context of web services (Zhu \& Kraemer, 2005). In another study, e-business value was studied using the TOE framework, which established a strong linkage between the three contextual factors with outcome achievement (Zhu, Kraemer, Xu, \& Dedrick, 2004). Park, Kim, and Paik (2015) tested the TOE framework in Korean firms and observed that its compatibility with the actual system, data quality, integration, and privacy and security were rated highly in a technology context.

The task-technology-fit (TTF) theory also has bearings on technology paradox formation. The TTF theory was developed by Goodhue and Thompson (1995), who stated that TTF is a pivotal concept in assessing and explaining the success of information systems (ISs). This theory focuses on individuals' use of ISs and introduces a fundamental positivistic research approach that can be applied to ISs in general. According to the TTF theory, a good fit between task characteristics and technology characteristics is responsible for better performance and more optimal usage of the technology (Goodhue \& Thompson, 1995). The TTF model is designed to investigate the actual usage of technology, particularly when it is new.

While the aforementioned theories address the technological aspects of paradoxes, some theories depend on the outcome of technology use in connection with performance in the workplace. The general perception is that the introduction of mobile technology in the workplace has increased employees' productivity, introduced more flexibility to work, and increased the efficiency of 
coordination among people (Jarvenpaa \& Lang 2005). However, ICTs in the form of smartphones introduce interruptions, data clutter, network problems, increased work pressure, and work-life imbalance (Fonner \& Roloff, 2010; Leonardi, Treem, \& Jackson, 2010; Mazmanian et al., 2013; Ter Hoeven et al., 2016; van Zoonen \& Rice, 2017). Smartphones feature multiple-use contexts and have changed the way technology is experienced by users (Middleton, Scheepers, \& Tuunainen, 2014). The ambiguities and inconsistencies that emerge from such technology can provoke internal conflicts or tensions among employees (Bruzzi \& Joia, 2015; Clegg et al., 2002). Repeated confrontation with the paradoxical aspects of technology sooner or later affects users' usage experience in general and their productivity and job performance in particular (Chae \& Yeum, 2010; Jarvenpaa \& Lang, 2005).

Job performance is a set of traits, behavior, and characteristics of the output of jobs undertaken by employees that contribute to organizational objectives. There are many different approaches to theories of job performance. According to the personality theory of job performance, the personality of an employee is a major determinant of performance (Barrick \& Mount, 1991), and five distinct dimensions of personalities have been identified in people-namely, extraversion, neuroticism, agreeableness, conscientiousness, and openness - each of which exhibits distinct traits in terms of action and behavior (Krausert, 2009).

Job experience theory (JET) is an advanced theory that postulates that people's job experience can help them handle unfamiliar situations better, thus enhancing their job performance (Schmidt \& Hunter, 2004). The subjectivity involved in the influence of experience on job performance was the main reason for the limited validity of the JET (Hunter \& Hunter, 1984). Testing the JET is more complex in comparison to other theories, as the experience of the employee does not necessarily need to be along the same lines as in the current job and may differ in terms of tasks handled, training undergone, responsibilities discharged, and so on. The major limitation of JET is that its validation is only possible with entry-level jobs, and when job performance must be evaluated for people with multiple job experiences, the theory does not do justice to the full range of their experiences (Krausert, 2009).

\section{RESEARCH METHOD}

Fundamentally, there are four types of methods used in literature review: evaluative, exploratory, instrumental, and systematic (Creswell \& Clark, 2017). This research adopted a systematic approach to reviewing literature mainly to help build a hypothesis for a future course of action, which can then be subjected to an empirical investigation. Moreover, a systematic review identifies, appraises, selects, and synthesizes evidence relevant to the research questions (Bolderston, 2008). Research originates with the identification of an area where there is a need to conduct further research due to the lack of earlier research (Ahmad \& Omar, 2016). The salient features of a systematic review are as follows: it can be replicated, the approach is scientific, and the process adopted is transparent (Khan, Kunz, Kleijnen, \& Antes, 2003). This method has been chosen over narrative research (Ferrari, 2015) because the systematic review should lead to clear research questions to be addressed and locate all published literature in databases; furthermore, it is necessary to identify what type of studies have to be included, to examine the methods used in these studies, and to identify methodologically sound and unsound studies. The five steps through which this systematic research process has been carried out are as follows.

\section{Defining Research Questions}

The first step in any research is to formulate the research problem. To obtain a comprehensive understanding of the models related to the technology paradox and job performance, two questions need to be addressed. 
Research Question 1: What is the current state of research regarding the models and theories about the dynamics of contextual factors, technology paradox, and employees' job performance?

Under this research question, two sets of models are reviewed: the first being contextual factors and technology paradox and the second linking technology paradox to job performance. The first two research constructs are treated as one because the research on contextual factors is multidimensional, and the focus here is only on the technology paradox.

Research Question 2: What are the focal themes of the research studies, and is there a gap in linking the three research constructs in an organizational context?

\section{Selecting Keywords and Search Strategy}

To find relevant research, the choice of the sources (e.g., reference databases, journals, or electronic databases) and the identification of the terms used to conduct searches are important (Cooper, 2017). Research started with the keywords "technology paradox," "paradoxes of technology," and "technology paradox and performance." The journals that had publications on the technology paradox included Emerald Insight, EBSCO Host, Google Scholar, JSTOR, Wiley Online, Springer link, SAGE Journal, Inder-Science, Science Direct, Taylor and Francis, and Elsevier. During the search, the scope of the search was limited to digital libraries. In terms of the period of the publication, the articles selected for systematic review ranged from January 1990 to December 2019. The reason for starting from 1990 was that active research on technology paradoxes grew in prominence during this period. The first paper was by McQuarrie and Iwamoto, published in 1990 in Social Science Computer Review (SAGE Journals), and the last paper, by Bissonnette and Arcand, was published in 2018 in the Journal of Entrepreneurship in the Arts (EBSCOhost).

The search string was then modified to suit the requirements of each individual journal during the search process. The keywords and search strings can be found in Table 1 .

The research at hand focused on the technology paradox, with specific reference to smartphones and job performance. However, there were few studies on this particular technology, and research on paradox, technology paradox, productivity paradox, and information systems paradox was previously undertaken by various researchers. Similarly, performance research also referred to the terms productivity and efficiency, which mainly referred to employee job performance. All these were considered, as they addressed the dimensions of paradox and job performance in different contexts that were relevant to the conceptual model development of this research.

\section{Assessing the Quality of Primary Studies}

Search strings were entered into the 37 databases, and a total of 549 articles were downloaded, out of which — after the titles and abstracts were read and considered based on relevance-it was found that only 395 were relevant in the context of technology paradox, performance, or both; 154 of the articles were eliminated. Among the 395 studies selected for inclusion, there were similar studies that would not add value to the research under consideration; thus, 135 studies were screened out, and 260 studies passed the criteria for inclusion and exclusion. After applying the inclusion criteria, 89 articles were excluded, and 171 studies qualified for quality assessment. Based on the quality of the papers, 81 papers were further rejected, and finally, 90 papers were considered fit for review based on the inclusion and exclusion criteria discussed in the next section (Figure 1). An overview of the search results is given in Table 2 .

\section{Inclusion Criteria}

This section delineates the characteristics of studies that qualified articles for inclusion in the study - mainly the setting of the study, participants in the research, outcome characteristics, and so 
Table 1. Search strings and Boolean operators

\begin{tabular}{|c|c|c|}
\hline Concept & Keywords and strings & Boolean operator \\
\hline Technology paradox theory & $\begin{array}{c}\text { [Technology AND Paradox] } \\
\text { [Theory OR Theories OR Model OR } \\
\text { Models OR System OR Systems OR } \\
\text { Concept OR Concepts] }\end{array}$ & AND \\
\hline Paradoxes of technology theory & $\begin{array}{c}\text { Paradoxes AND Technology } \\
\text { [Theory OR Theories OR Model OR } \\
\text { Models OR System OR Systems OR } \\
\text { Concept OR Concepts] }\end{array}$ & AND \\
\hline Technology and job performance \\
theory & $\begin{array}{c}\text { Technology AND Job performance } \\
\text { [Theory OR Theories OR Model OR } \\
\text { Models OR System OR Systems OR } \\
\text { Concept OR Concepts] }\end{array}$ & AND \\
\hline
\end{tabular}

Figure 1. The selection process for review, adapted from Moher, Liberati, Tetzlaff, Altman, \& PRISMA Group (2009)

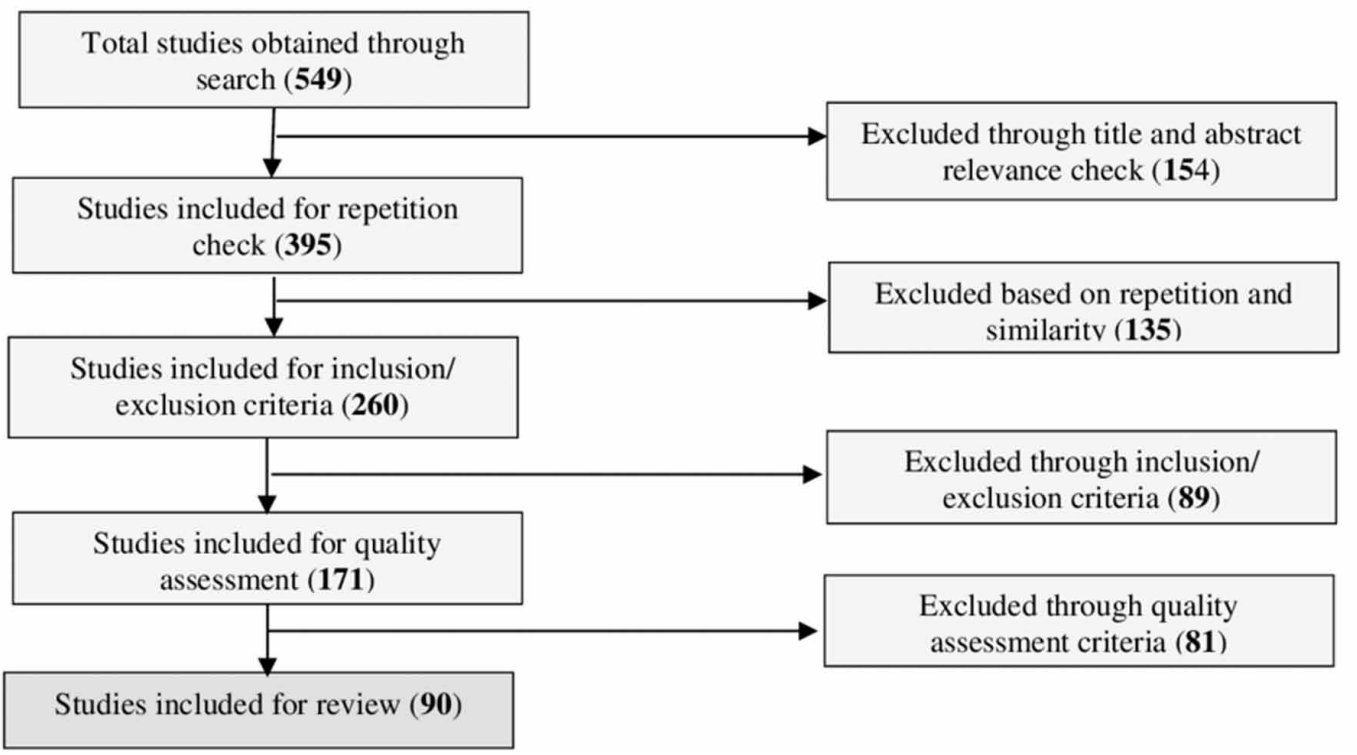

forth (Cooper, 2017). The type of research relevant and providing answers to the research questions had to explicitly address the two research constructs-technology paradox and job performance of employees-either individually or collectively. Each article also had to lead to the development of the framework, model, or underlying theories; had to be exploratory in addressing the factors that constitute technology paradox or that make employees perform in an organizational setup; and had to establish linkages between the dimensions of the technology paradox and job performance or explain the ability of the models in building the theory behind paradox formation due to the usage of technology. Additionally, studies included needed to explain the models' ability to contribute to theories behind job performance in an organizational setting, give alternate definitions and terminologies to the dimensions of the abovementioned research constructs, provide criticism of the theories under consideration, and record the empirical evidence for the existence of relationships 
Table 2. Overview of search results

\begin{tabular}{|c|c|c|c|c|c|}
\hline & $\begin{array}{c}\text { Papers } \\
\text { retrieved }\end{array}$ & $\begin{array}{c}\text { Papers } \\
\text { included }\end{array}$ & $\begin{array}{c}\text { Contextual } \\
\text { factors and } \\
\text { Technology } \\
\text { Paradox (CTP) }\end{array}$ & $\begin{array}{c}\text { Job } \\
\text { performance } \\
\text { (JP) }\end{array}$ & $\underset{\text { JP }}{\text { CTP \& }}$ \\
\hline 1. Academy of Management & 14 & 4 & 1 & 1 & 2 \\
\hline 2. American Psychological Association & 28 & 9 & 1 & 6 & 2 \\
\hline 3. Association of Information Systems & 12 & 1 & 0 & 1 & 0 \\
\hline 4. ASU Library & 22 & 1 & 1 & 0 & 0 \\
\hline 5. Cabell's Directory of Publishing Opportunities in Psychology & 16 & 1 & 0 & 1 & 0 \\
\hline 6. Central Archives - University of Reading & 13 & 2 & 0 & 1 & 1 \\
\hline 7. Claremont & 7 & 1 & 0 & 0 & 1 \\
\hline 8. Directory of Open Access Journals & 8 & 2 & 1 & 1 & 0 \\
\hline 9. EBSCO & 14 & 3 & 0 & 2 & 1 \\
\hline 10. Elsevier & 6 & 0 & 0 & 0 & 0 \\
\hline 11. Emerald Insight & 31 & 2 & 0 & 2 & 0 \\
\hline 12. ERIC & 21 & 2 & 1 & 1 & 0 \\
\hline 13. Ezine articles & 6 & 2 & 1 & 1 & 0 \\
\hline 14. Frontiers & 4 & 1 & 0 & 0 & 1 \\
\hline 15. German National Serials Database & 3 & 1 & 0 & 1 & 0 \\
\hline 16. Google Scholar & 6 & 0 & 0 & 0 & 0 \\
\hline 17. Harvard Business Press & 16 & 1 & 1 & 0 & 0 \\
\hline 18. Horizon Research & 8 & 1 & 1 & 0 & 0 \\
\hline 19. Ideas & 4 & 1 & 0 & 0 & 1 \\
\hline 20. InderScience & 18 & 1 & 1 & 0 & 0 \\
\hline 21. Index Copernicus & 17 & 1 & 0 & 1 & 0 \\
\hline 22. Information Systems \& Organizations & 10 & 1 & 0 & 0 & 1 \\
\hline 23. INFORMS pubs online & 6 & 3 & 2 & 0 & 1 \\
\hline 24. Ingenta Connect & 6 & 1 & 0 & 0 & 1 \\
\hline 25. JSTOR & 18 & 3 & 1 & 1 & 1 \\
\hline 26. Omnia Science & 7 & 1 & 0 & 1 & 0 \\
\hline 27. Open Access Research Database & 18 & 1 & 0 & 1 & 0 \\
\hline 28. Oxford Journals & 21 & 1 & 1 & 0 & 0 \\
\hline 29. Oxford University Press & 16 & 3 & 1 & 2 & 0 \\
\hline 30. ProQuest & 17 & 1 & 0 & 1 & 0 \\
\hline 31. Questia & 8 & 1 & 0 & 0 & 1 \\
\hline 32. SAGE & 26 & 9 & 1 & 6 & 2 \\
\hline 33. Science Direct & 21 & 12 & 4 & 5 & 3 \\
\hline 34. Springer & 35 & 3 & 1 & 1 & 1 \\
\hline 35. Taylor and Francis & 27 & 5 & 4 & 1 & 0 \\
\hline 36. Ulrich's Web Directory & 8 & 1 & 0 & 1 & 0 \\
\hline 37. Wiley Online Library & 31 & 7 & 1 & 5 & 1 \\
\hline Total & 549 & 90 & 25 & 44 & 21 \\
\hline
\end{tabular}

between the dimensions of the two research constructs. Finally, articles selected for inclusion also explicitly specified the methodological limitations of the theories on the two research constructs.

\section{Exclusion Criteria}

This section focuses on the criteria selected for excluding research articles initially chosen in the review process. In particular, these consisted of studies that did not correspond with the research question, such as studies that mentioned a primary focus on either technology paradox or job performance in the abstract, but did not address the issue adequately; studies that addressed the technology paradox in contexts not related to work environments; studies that addressed technology paradox theory 
building based on a productivity context; studies that focused on the theory of technology paradox with psychological influences, such as burnout; studies that addressed job performance theory building based on emotional and psychological aspects; or studies that were concerned with the influences of personality types on the development of the technology paradox. Finally, papers that were editorials, keynote addresses, tutorial summaries, books, technical reports, non-peer-reviewed articles, and similar ones with no definite journal publication record were also excluded.

\section{Quality Assessment}

One of the challenges in writing a review article involves the quality of the papers chosen for the study. While there are no standard definitions available for the quality of a review paper, the quality, to a considerable extent, may be context-based. As the present study is an evidence-based systematic review, only definitions of quality in connection to this method have been considered. Oxman (1994), in the context of medical research, emphasizes the importance of the internal validity of a study and states that the degree to which the research design has been successful in minimizing bias is the best estimate of the quality of a review. Mudavanhu (2017), in the context of educational research, states that the quality of a review paper is reflected in the choice of key sources, appropriate selection of the theories, quality of research questions, structure and organization of the content, accuracy of definition of the key terms, and extent to which the true knowledge available is understood. Again, in the context of the medical field, the quality of articles reviewed lies in their ability to build methodical orientation for future studies (Tran, Le, \& Vo, 2017). Many articles have highlighted other criteria for quality research reviews; however, in the interest of this research, the following criteria have been adopted to ensure the quality of this review.

The studies selected for review were chosen from peer-reviewed journals, and some were indexed by standard indexing bodies, such as ISI Web of Science, SCOPUS, Emerging Source Citation Index (ESCI), EBSCO A-to-Z, and Index Copernicus, etc. Initially, attempts were made to restrict the articles to only the first two of the aforementioned indexing databases, as they are considered to be standard references. However, as the technology paradox is not a very widely researched area and not many papers were available in these two databases, quality-oriented papers from other peer-reviewed journals were also used in this review. The quality assessment of these papers has been based on the objectives of the research, their contribution to theory building, their methods used to eliminate bias, the robustness of their research design, the accuracy of key definitions, evidence provided for establishing the linkages between the variables of the study, and the references used.

\section{Defining Data Extraction}

Data extraction was manually undertaken through characterization and classification, as recommended by Tranfield, Denyer, and Smart (2003); thus, they were based on general characteristics of the studies and classification schemes. The characteristics of the studies have been tabulated in the form shown in Table 3.

\section{Data Synthesis}

In this stage of the research, the classification scheme was thoroughly analyzed, which is later described in a separate section.

\section{Data Extraction}

Data extraction was undertaken based on the results obtained in previous steps that involved characterization and classification, which involved the following systematic steps. 
Table 3. Exclusion criteria and characteristics form

\begin{tabular}{|c|c|c|}
\hline & Exclusion criteria & $\begin{array}{l}\text { Characteristics and classification of } \\
\text { the study }\end{array}$ \\
\hline $\begin{array}{l}\text { Type of } \\
\text { publication }\end{array}$ & $\begin{array}{l}\square \text { Not peer-reviewed } \\
\text { Not Indexed }\end{array}$ & \\
\hline $\begin{array}{l}\text { Research } \\
\text { philosophy }\end{array}$ & $\square$ Transformational & $\begin{array}{l}\square \text { Constructivist } \\
\square \text { Positivist } \\
\square \text { Interpretivist } \\
\square \text { Pragmatic }\end{array}$ \\
\hline Research design & $\begin{array}{l}\square \text { Case Report } \\
\square \text { Conceptual paper }\end{array}$ & \begin{tabular}{|l}
$\begin{array}{l}\text { Observational } \\
\text { Intervention }\end{array}$ \\
\\
\\
\end{tabular} \\
\hline Source of data & $\begin{array}{l}\square \text { Hypothetical } \\
\square \text { Simulation }\end{array}$ & \begin{tabular}{|l}
$\square$ Interviews \\
$\square$ Surveys \\
$\square$ Content analysis \\
$\square$ Observation
\end{tabular} \\
\hline Sampling frame & & $\begin{array}{l}\square \text { Educational database } \\
\square \text { Corporate database } \\
\text { Municipality } \\
\square \text { Any other finite population }\end{array}$ \\
\hline $\begin{array}{l}\text { Characteristics } \\
\text { of respondents }\end{array}$ & & $\begin{array}{l}\square \text { Gender } \\
\square \text { Age } \\
\square \text { Educational qualifications } \\
\square \text { Marital status } \\
\square \text { Employment status } \\
\square \text { Work experience } \\
\square \text { Any other demographic variable }\end{array}$ \\
\hline $\begin{array}{l}\text { Outcome } \\
\text { measures and } \\
\text { results }\end{array}$ & $\square$ Non-generalizable & $\begin{array}{l}\square \text { Generalization } \\
\square \text { Theory building } \\
\square \text { Framework development } \\
\square \text { Empirical evidence } \\
\square \text { Work experience } \\
\text { Interpretation }\end{array}$ \\
\hline & \multicolumn{2}{|c|}{$\begin{array}{l}\text { None of the exclusion criteria fulfilled } \\
\text { One or more of the exclusion criteria fulfilled } \longrightarrow \text { Study included } \\
\end{array}$} \\
\hline
\end{tabular}

\section{General Characteristics of Included Studies}

The general characteristics of included studies were matched to the providing of answers to the research questions. The analysis was performed for publication trends, distribution of studies by databases, research methods used, and the journals in which they were mostly published.

\section{Classification Scheme}

The classification schemes relevant to this research are contribution, focus, and type of research, which are further discussed in the following sections. 


\section{Contribution Type}

The terms technology paradox and paradoxes of technology have been used interchangeably in the research literature. Thus, the following four classifications were made in this research:

1. Theories of paradox of technology

2. Theory of technology acceptance

3. Theories of job performance

4. Theories of paradox of technology and job performance

\section{Research Focus}

In the research under consideration, the following were important considerations in relation to the research focus of each of the studies.

1. Model development: These studies were primarily exploratory in nature, making attempts to develop a model to relate the research constructs of interest.

2. Model testing: These studies attempted to test the models that existed in specific areas of study.

3. Model adaptation: These studies were related to issues of adoption of the model in a given context.

4. Model advancement: These studies were related to the growth of the relevant studies over a period of time.

\section{Research Type}

The analysis resulted in the identification of seven different research types that were dominant in the research literature. The classification of these research types is presented in Table 4.

\section{Data Synthesis}

\section{General Characteristics}

As mentioned earlier, general characteristics were specific to the research questions of this research. Various types of research undertaken on the research constructs under consideration were identified. The articles involved different types of research, as displayed in Table 4. In terms of the distribution of papers based on the research constructs under review, out of the 90 papers that were examined, the greatest number of papers addressed job performance (44), followed by contextual factors and technology paradox (25); the remaining papers studied a combination of both research constructs (21). In examining the publication trends in the databases selected for this literature review, the greatest number of articles came from Science Direct (12), followed by the American Psychological Association and SAGE (9 each), and Wiley Online Library (7; Figure 2). None of the articles found in Google Scholar could be used in this research, as they were eliminated based on the quality assessment criteria applied to this research. In terms of the year of publication, the papers were categorized in terms of decades of publication, and it was found that the greatest number of publications relevant to this research was found in the year 2010 to 2015 (23), closely followed by 2015 to 2019 (18), and 2000 to 2005 (17), which indicates that research on the influence of the technology paradox on job performance of employees has been gaining popularity in recent years (Figure 3).

The variation in the number of articles published-in particular, the declining trend in the period 2005-2010, and then, a sudden increase in the next five years-may be attributed to several reasons. Initially, when smartphones were introduced and captured the markets, their usage during working hours was considered a hindrance to work, and the usage was discouraged. Several researchers even published articles on the psychological issues behind mobile phone usage and its repercussions for work-life balance (Bianchi \& Phillips, 2005); the focus was more on the cultural and economic aspects of mobile phone usage, either working on-site or outside (Wei \& Kolko, 2005). Furthermore, mobile 
Table 4. Classification of research studies and the description

\begin{tabular}{|c|c|}
\hline Type of Research & Description \\
\hline 1. Analytical & $\begin{array}{l}\text { Involves a critical evaluation of the available material by an in-depth study to explain } \\
\text { a complex phenomenon. }\end{array}$ \\
\hline 2. Empirical & Tests models or frameworks to provide empirical proof. \\
\hline 3. Viewpoint & Involves the author's interpretation of a situation, phenomenon, model, etc. \\
\hline 4. Conceptual & $\begin{array}{c}\text { Makes use of discursive and philosophical discussions leading toward the building of } \\
\text { hypotheses. }\end{array}$ \\
\hline 5. Case study & $\begin{array}{c}\text { Describes actual interventions or experiences and can be subjective to a considerable } \\
\text { extent. }\end{array}$ \\
\hline 6. Comparative study & $\begin{array}{l}\text { Illustrates convergence and divergence between various research projects on the same } \\
\text { topic. }\end{array}$ \\
\hline
\end{tabular}

capabilities were low in 2005, as smartphones were just becoming popular. For instance, iPhone usage was about 1 million in the year 2005, grew to about 40 million in 2010, but suddenly increased to nearly 230 million by 2015 and exponentially increased thereafter (Smartphone Addiction, 2020). Users are more likely to experience the paradoxical effects of mobile phones with new releases (Jarvenpaa \& Lang, 2005). Thus, issues of mobile phone usage in the workplace were not a very sought-after area of research during the period of 2005 to 2010 . However, as mobile phone usage suddenly increased during the period 2010 to 2015 , there appeared to be more focused research on mobile phone usage in the workplace. The year 2015 may be considered the saturation point, after which there was again a slight decrease, but it can be noted that this decrease was not as significant as in the years 2005 to 2010 . However, there was one article published in 1957 that was highly relevant to this research, as it had very focused research on the influence of technological changes on human behavior and was thus used in the literature review. The best databases for possible publication of research on the technology paradox and job performance were Science Direct, the American Psychological Association, SAGE, and the Wiley Online Library, as these sources included more studies recorded in relation to these research constructs. The papers reviewed may be classified into six groups, which are described in Table 4

\section{Outcome of the Classification Scheme and Research Questions}

The classification scheme of the literature reviewed in this research makes it imperative to distinguish between three major schemes of research in connection to the technology paradox: 1. theory building on technology paradox, 2. theory building on job performance, and 3. association between technology paradox and human behavior, affecting job performance. The first scheme focused on exploring the dimensions of the technology paradox and their antecedents, the second focused on exploring the dimensions of job performance, and the third focused on the influence of the technology paradox on human behavior, job performance, or both. The studies on human behavior were based on both individual well-being aspects as well as organizational aspects, such as performance, efficiency, and productivity. In terms of the research methods used in these studies, the majority of the studies were qualitative (85\%), a few studies were quantitative (11\%), and a small number were mixed methods based research (Figure 4). A mapping of the articles' contribution, research focus, and research type is depicted in Figure 5. While the diagram could be generated through software, the figure has been drawn manually to allow for greater customization. A total of 90 papers were reviewed, 25 of which addressed contextual factors and the technology paradox, 44 of which addressed job performance, and the remaining 21 of which addressed a combination of contextual factors and technology paradox and job performance. Among these 90 papers, 12 papers were analytical, four were empirical papers, 32 


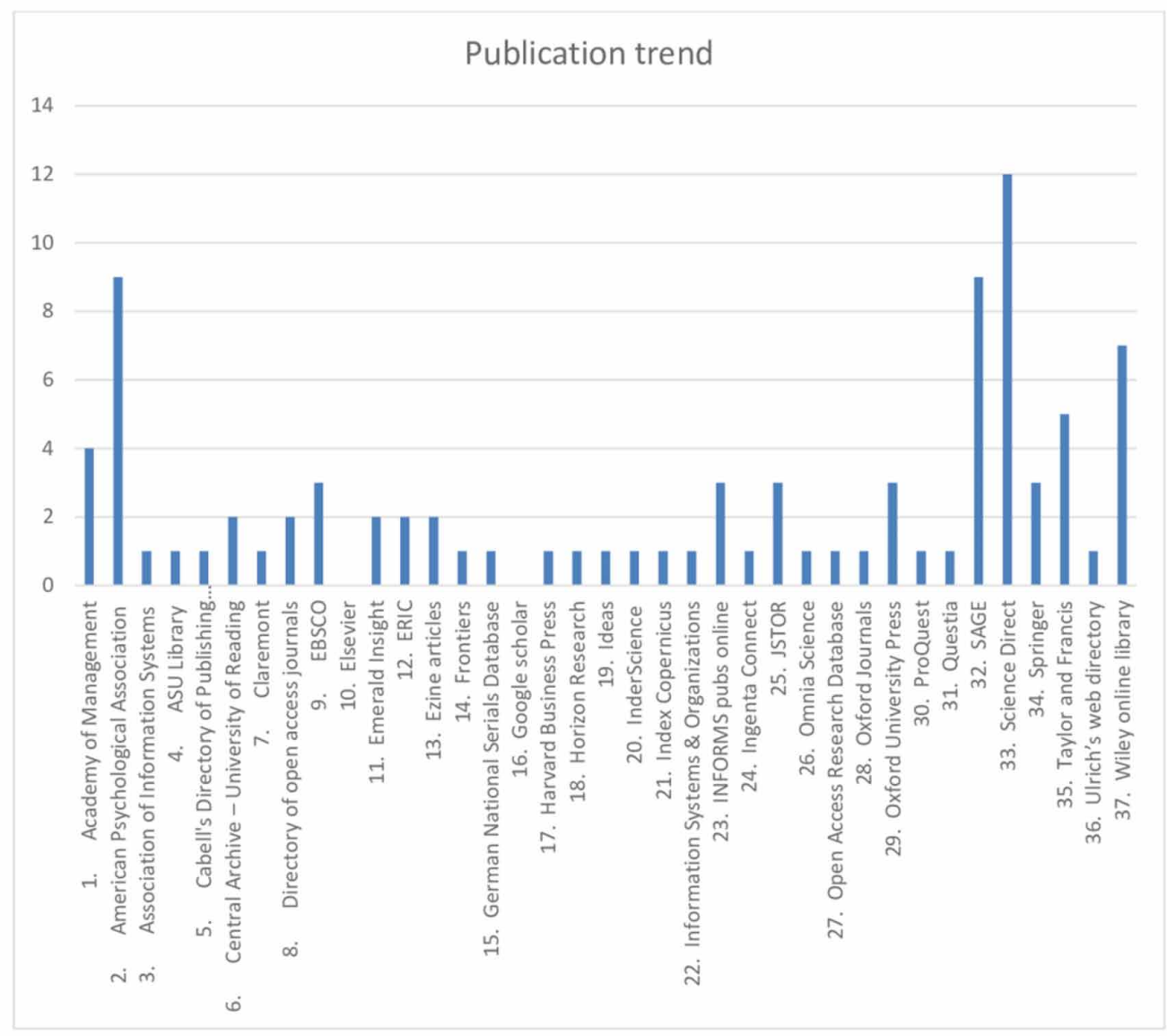

were viewpoint papers, 10 were conceptual papers, 29 were case studies, and seven were comparative studies. Furthermore, among the analytical papers, eight papers attempted model development, two involved model adaptation into a specific context, and the remaining two attempted model advancement. The four empirical papers focused on model advancement. Among the viewpoint papers, 15 papers involved model testing, 12 addressed model adaptation, and the remaining five attempted model advancement. Among the conceptual papers, three addressed model development, and seven concerned model advancement. Among the case study papers, 15 attempted model advancement, six involved model development, five concerned model testing, and three addressed model adaptation. Finally, among the comparative, study-based papers, four addressed model development, two conducted model testing, and one involved model adaptation. It can be observed that not a single paper specifically addressed the mediating effect of the technology paradox on the relationship between its contextual factors and employees' job performance. The following section is a discussion of the classification of research studies.

\section{Model Development}

Among the 30 papers that focused on model development, there was not a single paper relating contextual factors, the technology paradox, and job performance. However, separate studies have linked these three research constructs (e.g., Jarvenpaa \& Lang, 2005; Mazmanian, 2013; Mick \& 


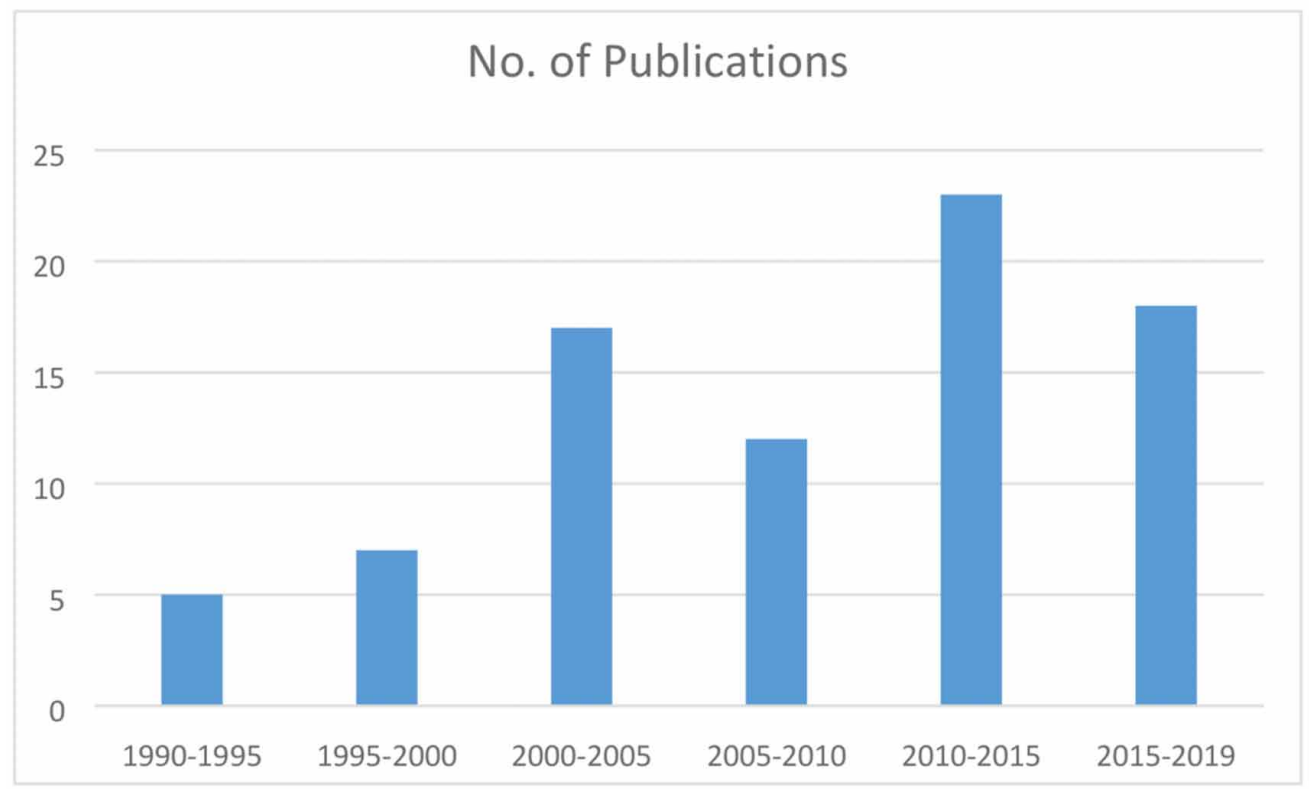

Fournier, 1998). The first paper that provided a comprehensive model of a technology paradox was by Mick and Fournier (1998). According to Mick and Fournier (1998), a paradox exists only if two contradictory things coexist; that is, "a paradox maintains that something is both $\mathrm{X}$ and not $\mathrm{X}$ at the same time" (p. 125). For instance, employees may feel free and empowered to use their mobile devices whenever they prefer, yet this perpetual connectivity also restricts their freedom to distance themselves from others (Jarvenpaa \& Lang, 2005). Regardless of the place and time, they may always be connected to their work (Chae \& Yeum, 2010). Thus, they simultaneously feel empowered and enslaved (Jarvenpaa \& Lang, 2005). Furthermore, paradoxes are dynamic and inevitable. They tend to change and evolve (Lewis, 2000) or interact with each other due to situational or individual factors that evoke fluctuating feelings, vacillating between contrary feelings or opinions (Jarvenpaa \& Lang, 2005; Mick \& Fournier, 1998).

Despite the importance of how individuals respond to paradoxes, which shapes the impact of the type of paradox they encounter (Jarzabkowiski et al., 2013), categorizing technological paradoxes remains the dominant thread addressed in the literature (Bruzzi \& Joia, 2015). The focus of this research is on literature that provides results of ICT use in an organizational context and the paradox that technologies create in the minds of employees (Jarvenpaa \& Lang, 2005; Leonardi et al., 2010; Mazmanian et al., 2013; Ter Hoeven et al., 2016; van Zoonen \& Rice, 2017), except one study from the field of consumer research and marketing by Mick and Fournier (1998). Mick and Fournier (1998) mainly focused on consumers' perspectives of technology paradoxes. Their focus was on awareness and coping strategies that consumers employ. They identified the most salient paradoxes as well as the ones that were tacit in the minds of technology consumers (Table 5).

\section{Model Testing}

There are relatively few papers (8) testing theories based on technology paradox or job performance; furthermore, research with empirical testing is rare. A study from Royal Court Affairs in Oman proved that employee motivation had a significant influence on job performance and that its impact 


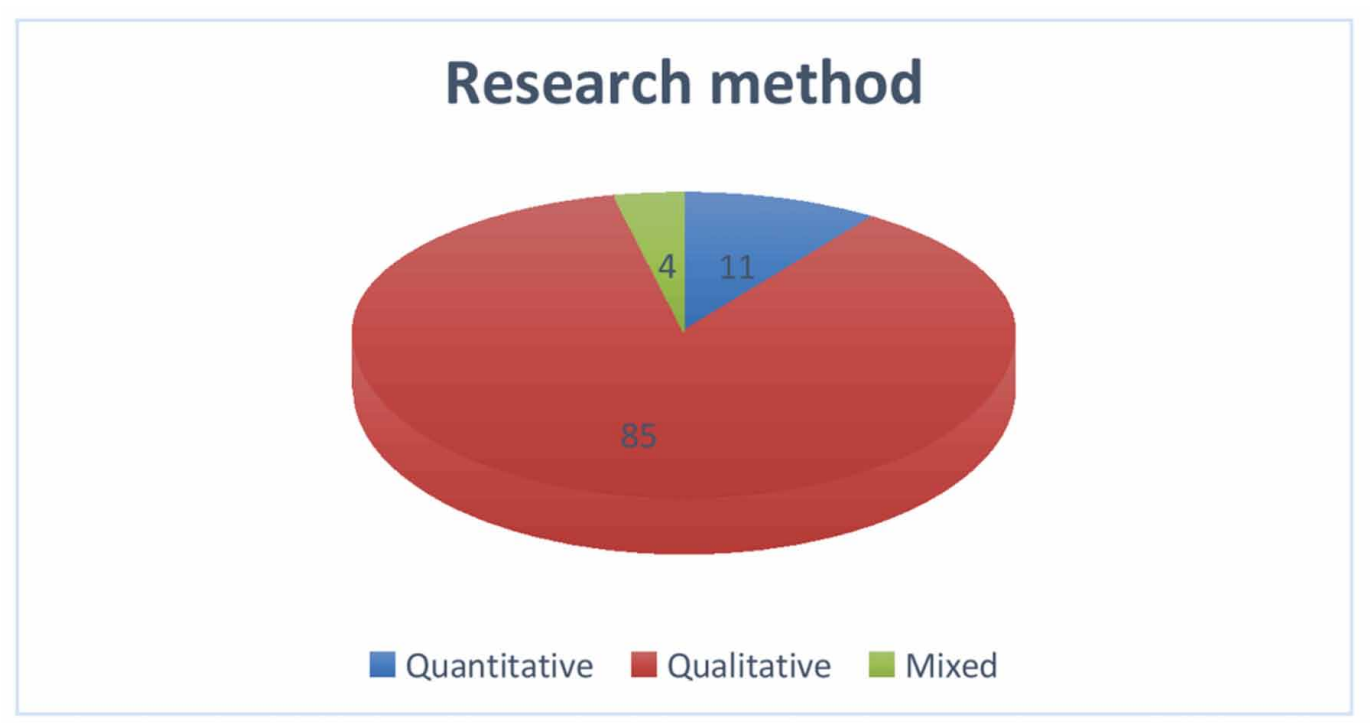

was as high as 67\% (Qatmeemalmarhoon, Mohdnoor, Abdalla, \& Musbah, 2017). A study on IT Park software developers in Pakistan, with a sample size of 200 and a six-dimension scale of natural and extraneous motivation, indicated that all the dimensions of motivation had a significant influence on job performance (Ali, Bin, \& Piang, 2016). In a study conducted at Kenya Commercial Bank, Mombasa, it was found that mutual trust, self-respect, and self-esteem acted as motivational factors that enhanced the job performance of the employees (Onanda, 2015). Bonsu and Kusi (2014) endorsed Herzberg's theory Y of motivation and, through a study of local government workers in Ghana, concluded that intrinsic factors provide better motivation to employees than extrinsic factors. It has been found that empowerment and recognition can be effective tools in motivating employees, which can, in turn, lead to better job performance (Dobre, 2013). There were also studies in which motivation had no significant influence on employee performance; however, remuneration had a positive impact on the job performance of the employee in the context of the employees at a food and beverage manufacturing company (e.g., Cahyanugroho, Hubeis \& Wijayanto, 2016).

\section{Model Adaptation}

There were 27 papers identified in the area of model adaptation in connection to contextual factors, technology paradox, and job performance. There are several distinctive theories in these areas that have been discussed in earlier sections. The one that is specific to the technology paradox context is the theory proposed by Lai (2017), who comprehensively reviewed the concepts, applications, and development of technology adoption models and potential applications for the novelty of technology. The adoption of technology has been linked by the theory of reasoned action (TRA) (Fishbein \& Ajzen, 1975), theory of planned behavior (TPB; Ajzen, 1985), decomposed theory of planned behavior (DTPB; Taylor \& Todd, 1995), technology acceptance model (TAM; Davis, Bogozzi, \& Warshaw, 1989), TAM2 (Venkatesh \& Davis, 2000), and TAM3 (Venkatesh \& Bala, 2008). Lai's (2017) paper provided a theoretical background, research problems, the parameters involved, and measurements in the context of technology adoption. However, much remains to be done, specifically in terms of the issues related to the behavioral aspects of the employees in the adoption of newer technology, which keeps changing at a pace that has never been seen before. 
Figure 5. Research focus map

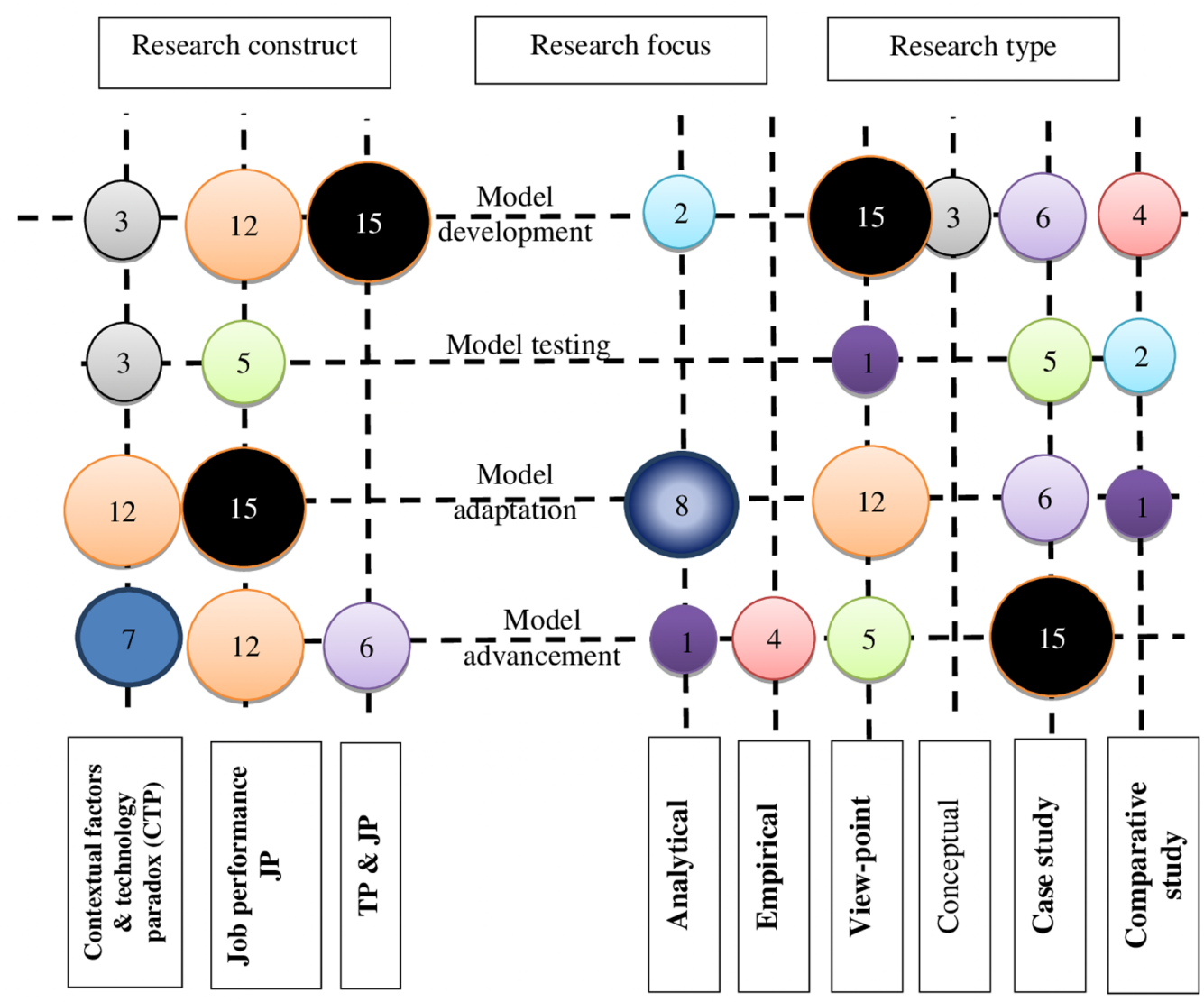

Table 5. Paradoxes of technology adapted from Mick and Fournier (1998)

\begin{tabular}{|c|c|}
\hline Technology Paradox & Observation \\
\hline Control-chaos & Technology has the potential to create order or chaos. \\
\hline Freedom-enslavement & Technology can liberate as well as shackle. \\
\hline New-obsolete & Technologies can emancipate knowledge as well as erode it. \\
\hline Competence-incompetence & $\begin{array}{c}\text { Technology can enhance intelligence or efficacy but can also lead to ignorance or } \\
\text { ineffectiveness. }\end{array}$ \\
\hline Efficiency-inefficiency & Technology can reduce resource consumption as well as increase it. \\
\hline Fulfills-creates needs & Technology can meet needs or even lead to the creation of more. \\
\hline Assimilation-isolation & Technology may aid human integration but may also lead to isolation. \\
\hline Engaging-disengaging & Technology can network people or promote passivity. \\
\hline
\end{tabular}




\section{Model Advancement}

There have been 25 articles on model advancement in the context of technology paradox and job performance dynamics. There have been multiple attempts to advance models of contextual factors, technology paradox, and job performance. Even though there are several studies regarding the advancement of the technology paradox model developed by Mick and Fournier (1998), a noticeable contribution came from Chae and Yeum (2010), who not only tested the model but also began to explore reasoning for paradox formation. Chae and Yeum formulated hypotheses based on the model and tested them $(n=172)$. The independent variables in their research were paradoxes and propensity of the mobile technology paradox, and the dependent variable was coping strategies. Researchers have found that the majority of the participants were cognizant of the contradictory aspects of mobile technology. Furthermore, these contradictory aspects had a strong correlation between technology paradoxes and were considered to be responsible for reduced mobile consumption. Such findings substantiate the findings of earlier studies on the technology paradox, such as Mick and Fournier's (1998) study, which noted that paradoxes such as empowerment-enslavement, efficiency-inefficiency, and new-obsolete were among the salient paradoxes that emerged due to users' repeated confrontation with the contradictory attributes of technologies.

Furthermore, researchers found that mobile users' perceptions of mobile technology paradoxes are susceptible to changes, with the frequent use of such devices, when users become more experienced with mobile device usage. For example, changes in users' perceptions of public-private and planningimprovisation paradoxes were evident in their responses, as such paradoxes that were once in conflict were subsequently considered benefits. Furthermore, the improvisation that mobile devices allow for has contributed to better job performance by helping users to do their jobs efficiently. Similarly, the public-private paradox that manifested in previous studies as a mobile technology paradox - that is, an issue recognized by mobile users - was found to be less important and less likely to cause a conflict in mobile users' experiences (Chae \& Yeum, 2010). Thus, such findings in Chae and Yeum's (2010) study contradict earlier findings by Jarvenpaa and Lang (2005), who viewed the abovementioned paradoxes as "conflicting situations" that generate tension and need to be mitigated through coping strategies. However, the changes in perceptions of the paradoxes align with the previous studies by Mick and Fournier (1998) and Smith and Lewis (2011), who noted that paradoxes are dynamic, as they tend to evolve, change, and fade in and out people's lives. The dynamic nature of a paradox explains why users' perception of existing technology paradoxes in the literature is likely to change, and as a result, those paradoxes need to be verified in newer contexts.

\section{DISCUSSION}

This literature review has been conducted to specifically address the two research questions. While the first research question concerned the underpinning theoretical models of the research constructs, the second was related to the identification of a research gap.

The foundational model to the research on technology paradox originates from Mick and Fournier (1998), which has yielded eight technology paradoxes; however, ambiguity among the dimensions was an issue that needed to be addressed. Arnold (2003) adopted a metaphorical approach to the technology paradox that proved that the use of metaphor could enhance technology performance. Even though this study was purely qualitative, it resulted in the identification of 22 factors linked to the affordances of technology. The second breakthrough in the research on the technology paradox was provided by Jarvenpaa and Lang (2005), who eliminated the issue of ambiguity in the dimensions of the technology paradox in the context of mobile technology. Even though this research was a significant contribution to the research on technology paradoxes, as it considered the effect of situational factors, the study lacked empirical evidence to support linkages between the identified dimensions. Middleton (2007) countered some of the dimensions and further fine-tuned the dimensions of the technology paradox. Johnson et al. (2008) added theoretical and managerial implications to the technology paradox, identifying the overlap between some of the dimensions and 
further fine-tuning the dimensions of the technology paradox. Chae and Yeum (2010) exclusively explored the managerial component of the technology paradox and provided a technical attributeoriented or managerial attribute-oriented perspective to the research on the technology paradox. Fonner and Roloff (2010) initiated a well-documented empirical investigation of the relationships between the dimensions of the technology paradox and work-life balance. Barley, Meyerson, and Grodal (2011) provided the social and cultural dimensions to the issue of the technology paradox. Zhuang, Hsu, Brewer, and Xiao (2012) established linkages between the technology paradox and customer loyalty. Borges and Joia (2014) observed gender differences in perceptions of the technology paradox. Cavazotte, Lemos, and Villadsen (2014) disproved the autonomy paradox, with specific reference to smartphones. Ter Hoeven et al. (2016) linked the technology paradox to the well-being of employees, as it had a bearing on their job performance. Ratna and Kaur (2016) associated the technology paradox with the employees' job performance. Van Zoonen and Rice (2017) linked the contradictory effect of the personal social media paradox for work on employees' autonomy and work pressure. While these are prominent research breakthroughs in technology paradox research, there have been many other studies not directly related to the dynamics of contextual factors, technology paradox, and job performance, which are the primary focus of this research. While these discussions address the first research question posed, the next issue is the seven research gaps, which have been listed in Table 6 .

\section{CONCLUSION}

This literature review indicates that researchers have utilized qualitative and quantitative research methods to study the technology paradox; however, few studies have adopted a mixed-methods approach. There is evidence for qualitative studies based on the grounded theory approach. In those qualitative studies, data collection has taken place through a combination of techniques that included interviews, discussions, semi-structured in-depth interviews, and questionnaires. Some researchers have used thematic analysis and identified patterns based on the response of the participants in the survey.

There have been different threads of research on technology paradox that include technology consumers' perspectives, the performance of technology, mobile users' perspectives, work-life conflict, satisfaction with technologies, coping strategies, a comparison between teleworkers and office workers, technology-enabled communication, social networking, gender role, flexible workflow design, etc. Most of these studies have attempted to understand the technology paradox better and have either provided evidence for respondents' agreement or disagreement with the paradox. Researchers have also studied the mediating influences of factors associated with technology paradoxes to gain insight into the impact they can have on the respondents. Through the research gap identified in this paper, it can be concluded that there is a necessity to conduct empirical research to study the role of the technology paradoxes in mobile technology usage in business environments to explore their influence on the job performance of employees. The practical implication of this literature review is the identification of seven specific research gaps in the existing literature, opening up new directions for further research on each of these gaps. For instance, the first gap is on the contradictory evidence, and the resolution of conflicts in defining the identified paradoxes could facilitate the mitigation of the ill effects of these paradoxes, ultimately allowing employees to use mobile technology more effectively in the workplace. Similarly, the action-knowledge conflict type of gap is an avenue for future research to secure empirical proof for the existence of relationships between specific technology paradoxes, particularly in the context of mobile phone usage in the workplace, which could be very useful to human resources managers seeking to help employees make effective use of mobile technology. The theoretical implication of this systematic literature review is that it has linked the three major focal themes that have been studied discretely so far in the literature. In this era of smartphone usage in the work environment, the technology paradox and its role in job performance is an important research topic, and more research studies in this direction can be envisaged. 
Table 6. Research gaps identified in the literature

\begin{tabular}{|c|c|}
\hline Type of Gap & Sources \\
\hline $\begin{array}{l}\text { 1. Contradictory } \\
\text { Evidence }\end{array}$ & $\begin{array}{l}\text { Mick and Fournier (1998) have identified eight technology paradoxes that were later refined by Jarvenpaa and Lang } \\
\text { (2005). Middleton (2007), Fonner and Roloff (2010), Barley et al. (2011), Cavazotte et al. (2014), and Ter Hoeven et al. } \\
\text { (2016) have countered these technology paradoxes in different contexts, including the use of ICTs in the form of mobile } \\
\text { phones. Thus, these conflicting results fall under the contradictory evidence (Jacobs, 2011; Müller-Bloch \& Kranz, } \\
2015 \text { ) category of research gap, a gap that needs to be filled. }\end{array}$ \\
\hline 2. Knowledge Void Gap & $\begin{array}{l}\text { Research on the technology paradox (e.g., Fonner \& Roloff, 2010; Middleton \& Cukier, 2006) has shown } \\
\text { that work intensification helps employees meet multiple demands of their jobs, thereby forming a negative } \\
\text { correlation between information exchange frequency and work-life balance, resulting in better management of } \\
\text { their lives. Similarly, unwitting enrollment in practices of work expansion intensified control of the employees } \\
\text { (e.g., Cavazotte et al., 2014). Therefore, these studies need to be extended to other domains of employees' jobs } \\
\text { and new contexts. Thus, all these can be categorized as knowledge void gaps (Jacobs, 2011) that must be filled. }\end{array}$ \\
\hline $\begin{array}{l}\text { 3. Practical Knowledge } \\
\text { Gap }\end{array}$ & $\begin{array}{l}\text { Several studies qualitatively identified the technology paradoxes (e.g., Cavazotte et al., 2014; Mazmanian } \\
\text { et al., 2013; Middleton, 2007). Additionally, theoretical models (e.g., Jarvenpaa \& Lang, 2005; Mick \& } \\
\text { Fournier, 1998) that illustrate the role of the technology paradoxes have been developed, but there has been a } \\
\text { lack of studies in practical situations that supports extant models in the literature. This constitutes the action- } \\
\text { knowledge conflict or the practical knowledge gap (Müller-Bloch \& Kranz, 2015) that needs to be filled. }\end{array}$ \\
\hline $\begin{array}{l}\text { 4. Methodological } \\
\text { Conflict }\end{array}$ & $\begin{array}{l}\text { Most of the studies on the phenomenon of the technology paradox have been heavily reliant on qualitative approaches, } \\
\text { whereas quantitative studies are scarce, as examining paradoxes challenges traditional quantitative methods (Schad, Lewis, } \\
\text { Raisch, \& Smith, 2016). Similarly, there are very few studies using a mixed-methods approach, but the studies' results do } \\
\text { not accord with each other due to the influence of the methodology on the research results. Thus, a gap exists between the } \\
\text { desired and current state of research that constitutes the type of research gap referred to as a methodological conflict (Jacobs, } \\
\text { 2011). Thus, a variation in research methods is recommended, especially if the topic has been addressed using a common } \\
\text { or a particular method (Müller-Bloch \& Kranz, 2015), such as the qualitative method used to study the technology paradox. }\end{array}$ \\
\hline $\begin{array}{l}\text { 5. Evaluation Void or } \\
\text { Empirical Gap }\end{array}$ & $\begin{array}{l}\text { There are studies examining the association between technology and consumer performance ambiguity (e.g., Johnson et } \\
\text { al., 2008), studies on the technology paradox and coping strategies (e.g., Chae \& Yeum, 2010; Jarvenpaa \& Lang, 2005; } \\
\text { Mick \& Fournier, 1998), studies on technology usage and management of life (e.g., Cavazotte et al., 2014; Fonner \& Roloff, } \\
\text { 2010; Middleton, 2007), studies relating technology with social and cultural aspects (e.g., Barley et al., 2011), studies } \\
\text { on paradoxes involving social networking sites and customer loyalty (e.g., Zhuang et al., 2012), studies on technology } \\
\text { and gender role (e.g., Borges \& Joia, 2014; Bruzzi \& Joia, 2015), and studies on technology and flexible workflow } \\
\text { design (e.g., Ter Hoeven et al., 2016), but there is a lack of evidence or of an empirical study on the relationship among } \\
\text { contextual factors, technology paradoxes, and job performance of employees, which is vital to the organizational growth } \\
\text { point of view. This constitutes an evaluation void or empirical gap (Müller-Bloch \& Kranz, 2015) that needs to be filled. }\end{array}$ \\
\hline $\begin{array}{l}\text { 6. Theory Application } \\
\text { Void Gap }\end{array}$ & $\begin{array}{l}\text { A theory application void gap (Jacobs, 2011; Müller-Bloch \& Kranz, 2015) exists because the technology } \\
\text { paradox phenomenon has been addressed using a common "qualitative" method, which resulted in the lack of } \\
\text { theory application that would allow for the generation of new insights. Using the theory of paradox to enrich } \\
\text { extant technology and job performance theories can help researchers understand how the associated theories } \\
\text { provide newer perspectives to behavioral influences on performance, as well as the nature of handling of tensions, } \\
\text { which, in turn, can provide more theoretical insights as well as managerial prescriptions (Lewis \& Smith, 2014). }\end{array}$ \\
\hline $\begin{array}{l}\text { 7. Population Group or } \\
\text { Under-researched Sub- } \\
\text { Groups Gap }\end{array}$ & $\begin{array}{l}\text { Few scholars have studied the role of age (e.g., Mick \& Fournier, 1998) and gender (e.g., Borges \& Joia, 2014; Bruzzi } \\
\text { \& Joia, 2015) in the technology paradox. The impact of gender in accentuating paradoxes due to smartphone use is } \\
\text { relatively new in the field of IS (Borges \& Joia, 2014). Specific individual factors, such as gender and age, have a } \\
\text { role in how one perceives and recognizes a technology paradox. Thus, the association between demographics and the } \\
\text { technology paradox is under-researched. Furthermore, prevalent studies on the technology paradox have been limited to } \\
\text { the context of western countries; therefore, the outcomes of the studies undertaken in western societies (individualistic), } \\
\text { particularly on individual characteristics, cannot be generalized into more collectivist societies. One's behavior is } \\
\text { influenced by the culture of society, which, in turn, has a bearing on organizational culture and job performance (Paschal } \\
\& \text { Nizam, 2016). For that reason, it is imperative to study such paradoxical tensions in a new context, as the cognitive } \\
\text { frames imposed by national culture inform individuals' cognition when facing tensions (Smith et al., 2017). Therefore, } \\
\text { there is a population group or under-researched sub-groups gap (Robinson, Saldanha, \& Mckoy, 2011) to be filled. }\end{array}$ \\
\hline
\end{tabular}




\section{REFERENCES}

Ahmad, S., \& Omar, R. (2016). Basic corporate governance models: A systematic review. International Journal of Law and Management, 58(1), 73-107. doi:10.1108/IJLMA-10-2014-0057

Ajzen, I. (1985). From intentions to actions: A theory of planned behavior. In J. Kuhi \& J. Beckmann (Eds.), Action-control: From cognition to behavior (pp. 11-39). Springer., doi:10.1007/978-3-642-69746-3_2

Ali, A., Bin, L. Z., Piang, H. J., \& Ali, Z. (2016). The impact of motivation on the employee performance and job satisfaction in park (software house) sector of Peshawar, Pakistan. International Journal of Academic Research in Business \& Social Sciences, 6(9), 297-310. doi:10.6007/IJARBSS/v6-i9/2311

Andriopoulos, C., \& Gotsi, M. (2017). Methods of paradox. In W. K. Smith, P. Jarzabkowski, M. W. Lewis, \& A. Langley (Eds.), The Oxford Handbook of Organizational Paradox (pp. 513-527)., doi:10.1093/ oxfordhb/9780198754428.013.26

Arnold, M. (2003). On the phenomenology of technology: The "Janus-faces" of mobile phones. Information and Organization, 13(4), 231-256. doi:10.1016/S1471-7727(03)00013-7

Barley, S. R., Meyerson, D. E., \& Grodal, S. (2011). E-mail as a source and symbol of stress. Organization Science, 22(4), 887-906. doi:10.1287/orsc.1100.0573

Barrick, M. R., \& Mount, M. K. (1991). The big five personality dimensions and job performance: A meta analysis. Personnel Psychology, 44(1), 1-26. doi:10.1111/j.1744-6570.1991.tb00688.x

Bianchi, A., \& Phillips, J. G. (2005). Psychological predictors of problem mobile phone use. [PubMed]. Cyberpsychology \& Behavior, 8(1), 39-51. doi:10.1089/cpb.2005.8.39

Bissonnette, J., \& Arcand, S. (2018). Music entrepreneurs in a linguistic minority context: Effectuation as adaptation to the paradoxes of digital technologies. Artivate, 7(1), 3-22. doi:10.34053/artivate.7.1.003

Bolderston, A. (2008). Writing an effective literature review. Journal of Medical Imaging and Radiation Sciences, 39(2), 86-92. doi:10.1016/j.jmir.2008.04.009

Bonsu, C. A., \& Kusi, A. (2014). Effects of motivation on job performance of local government workers in Ghana: A case study of Atwima Nwabiagya district assembly in the Ashanti Region. International Journal of Management Sciences, 2(8), 337-250.

Borges, A. P., \& Joia, L. A. (2014). The role of gender in paradoxes associated with smartphone use by Brazilian executives. Paper presented at the 20th Americas Conference on Information Systems, AMCIS 2014. Retrieved from www.scopus.com

Bruzzi, P., \& Joia, L. A. (2015). Detecting and sorting the paradoxes associated with smartphone use by Brazilian professionals. Paper presented at the 2015 Americas Conference on Information Systems, AMCIS 2015. Retrieved from www.scopus.com

Buettner, R. (2015). Towards a new personal information technology acceptance model: conceptualization and empirical evidence from a bring your own device dataset. 21st Americas Conference on Information Systems, AMCIS 2015.

Cahyanugroho, A., Hubeis, M., \& Wijayanto, H. (2016). The effect of remuneration on motivation that implicates employee's performance in XYZ company. Indonesian Journal of Business and Entrepreneurship, 2(2), $112-122$. doi:10.17358/IJBE.2.2.112

Cavazotte, F., Lemos, A., \& Villadsen, K. (2014). Corporate smart-phones: Professionals' conscious engagement in escalating work connectivity. New Technology, Work and Employment, 29(1), 72-87. doi:10.1111/ntwe.12022

Chae, M. S., \& Yeum, D. S. (2010). The impact of mobile technology paradox perception and personal risk-taking behaviours on mobile technology adoption. Management Science and Financial Engineering, 16(2), 115-138.

Clegg, S. R., Cunha, J., Pina, E., \& Cunha, M. (2002). Management paradoxes: A relational view. Human Relations, 55(5), 483-503. doi:10.1177/0018726702555001

Cooper, H. (2017). Research synthesis and meta-analysis: A step-by-step approach. Sage Publications. 
Creswell, J. W., \& Clark, V. L. P. (2017). Designing and conducting mixed methods research. Sage Publications.

Cullen, K. L., Edwards, B. D., Casper, W. C., \& Gue, K. R. (2014). Employees' adaptability and perceptions of change-related uncertainty: Implications for perceived organizational support, job satisfaction, and performance. Journal of Business and Psychology, 29(2), 269-280. doi:10.1007/s10869-013-9312-y

Davis, F. D., Bagozzi, R. P., \& Warshaw, P. R. (1989). User acceptance of computer technology: A comparison of two theoretical models. Management Science, 35(8), 982-1003. doi:10.1287/mnsc.35.8.982

Dobre, O. I. (2013). Employee motivation and organizational performance. Review of Applied Socio-Economic Research, 5(1), 53-60.

Ferrari, R. (2015). Writing narrative style literature reviews. Medical Writing, 24(4), 230-235. doi:10.1179/2 $047480615 Z .000000000329$

Fishbein, M., \& Ajzen, L. (1975). Belief, attitude, intention, and behavior: An introduction to theory and research. Addison-Wesley.

Fonner, K. L., \& Roloff, M. E. (2010). Why teleworkers are more satisfied with their jobs than are office-based workers: When less contact is beneficial. Journal of Applied Communication Research, 38(4), 336-361. doi:1 $0.1080 / 00909882.2010 .513998$

Goodhue, D. L., \& Thompson, R. L. (1995). Task-technology fit and individual performance. MIS Quarterly: Management. Information Systems, 19(2), 213-233. www.scopus.com

Hagger, M. S. (2019). The reasoned action approach and the theories of reasoned action and planned behavior. In D. S. Dunn (Ed.), Oxford Bibliographies in Psychology. Oxford University Press., doi:10.1093/ obo/9780199828340-0240

Hunter, J. E., \& Hunter, R. F. (1984). Validity and utility of alternative predictors of job performance. Psychological Bulletin, 96(1), 72-98. doi:10.1037/0033-2909.96.1.72

Jacobs, R. L. (2011). Developing a research problem and purpose statement. In T. S. Rocco \& T. G. Hatcher (Eds.), The Handbook of Scholarly Writing and Publishing (pp. 125-141). Jossey-Bass.

Jarvenpaa, S. L., \& Lang, K. R. (2005). Managing the paradoxes of mobile technology. Information Systems Management, 22(4), 7-23. doi:10.1201/1078.10580530/45520.22.4.20050901/90026.2

Jarzabkowski, P., Lê, J. K., \& Van de Ven, A. H. (2013). Responding to competing strategic demands: How organizing, belonging, and performing paradoxes coevolve. Strategic Organization, 11(3), $245-280$. doi:10.1177/1476127013481016

Johnson, D. S., Bardhi, F., \& Dunn, D. T. (2008). Understanding how technology paradoxes affect customer satisfaction with self-service technology: The role of performance ambiguity and trust in technology. Psychology and Marketing, 25(5), 416-443. doi:10.1002/mar.20218

Khan, K. S., Kunz, R., Kleijnen, J., \& Antes, G. (2003). Five steps to conducting a systematic review. Journal of the Royal Society of Medicine, 96(3), 118-121. doi:10.1177/014107680309600304

Krausert, A. (2009). Performance management for different employee groups: A contribution to employment systems theory. Springer Science \& Business Media. doi:10.1007/978-3-7908-2197-0

Lai, P. C. (2017). The literature review of technology adoption models and theories for the novelty technology. Journal of Information Systems and Technology Management, 14(1), 21-38. doi:10.4301/S180717752017000100002

Leonardi, P. M., Treem, J. W., \& Jackson, M. H. (2010). The connectivity paradox: Using technology to both decrease and increase perceptions of distance in distributed work arrangements. Journal of Applied Communication Research, 38(1), 85-105. doi:10.1080/00909880903483599

Lewis, M. W. (2000). Exploring paradox: Toward a more comprehensive guide. Academy of Management Review, 25(4), 760-776. doi:10.5465/amr.2000.3707712

Lewis, M. W., \& Smith, W. K. (2014). Paradox as a metatheoretical perspective: Sharpening the focus and widening the scope. The Journal of Applied Behavioral Science, 50(2), 127-149. doi:10.1177/0021886314522322 
Maulani, G. A. F., \& Hamdani, N. A. (2019). The influence of information technology and organizational climate on the competitiveness of private universities in Indonesia. International Journal of Recent Technology and Engineering, 8(1S), 142-145. www.scopus.com

Mazmanian, M., Orlikowski, W. J., \& Yates, J. (2013). The autonomy paradox: The implications of mobile email devices for knowledge professionals. Organization Science, 24(5), 1337-1357. doi:10.1287/orsc.1120.0806

Mcquarrie, E. F., \& Iwamoto, K. (1990). Public opinion toward computers as a function of exposure. Social Science Computer Review, 8(2), 221-233. doi:10.1177/089443939000800204

Micheni, E. M. (2015). Using the technology organization environment framework for adoption and implementation of cloud computing in institutions of higher learning in Kenya. International Journal of Engineering Science, 4(9), 37-43.

Mick, D. G., \& Fournier, S. (1998). Paradoxes of technology: Consumer cognizance, emotions, and coping strategies. The Journal of Consumer Research, 25(2), 123-143. doi:10.1086/209531

Middleton, C., Scheepers, R., \& Tuunainen, V. K. (2014). When mobile is the norm: Researching mobile information systems and mobility as post-adoption phenomena. European Journal of Information Systems, 23(5), 503-512. doi:10.1057/ejis.2014.21

Middleton, C. A. (2007). Illusions of balance and control in an always-on environment: A case study of BlackBerry users. Continuum, 21(2), 165-178. doi:10.1080/10304310701268695

Middleton, C. A., \& Cukier, W. (2006). Is mobile email functional or dysfunctional? Two perspectives on mobile email usage. European Journal of Information Systems, 15(3), 252-260. doi:10.1057/palgrave.ejis.3000614

Moher, D., Liberati, A., Tetzlaff, J., \& Altman, D. G.PRISMA Group. (2009). Preferred reporting items for systematic reviews and meta-analyses: The PRISMA statement. Journal of Clinical Epidemiology, 62(10), 1006-1012. doi:10.1016/j.jclinepi.2009.06.005

Mudavanhu, Y. (2017). Quality of literature review and discussion of findings in selected papers on integration of ICT in teaching, role of mentors, and teaching science through science, technology, engineering, and mathematics (STEM). Educational Research Review, 12(4), 189-201. doi:10.5897/ERR2016.3088

Müller-Bloch, C., \& Kranz, J. (2015). A framework for rigorously identifying research gaps in qualitative literature reviews. Paper presented at the 2015 International Conference on Information Systems: Exploring the Information Frontier, ICIS 2015. Retrieved from www.scopus.com

Onanda, B. (2015). The effects of motivation on job performance: A case study of KCB Coast Region. International Journal of Scientific and Research Publications, 5(9), 22-31.

Otieno, O. C., Liyala, S., Odongo, B. C., \& Abeka, S. (2016). Theory of reasoned action as an underpinning to technological innovation adoption studies. World Journal of Computer Application and Technology, 4(1), 1-7. doi:10.13189/wjcat.2016.040101

Oxman, A. D. (1994). Systematic reviews: Checklists for review articles. BMJ (Clinical Research Ed.), 309(6955), 648-651. doi:10.1136/bmj.309.6955.648

Park, J. H., Kim, M. K., \& Paik, J. H. (2015). The factors of technology, organization, and environment influencing the adoption and usage of big data in Korean Firms. Proceedings of 26th European Regional ITS Conference.

Paschal, A. O., \& Nizam, I. (2016). Effects of organizational culture on employees' performance: Case of Singapore telecommunication. International Journal of Accounting \& Business Management, 4(1), 19-26. doi:10.24924/ijabm/2016.04/v4.iss1/19.26

Qatmeemalmarhoon, A. B. A. S., Mohdnoor, K. B., Abdalla, M. A. D., \& Musbah, A. R. (2017). Effect of motivation on employees' performance and employees' commitment. International Journal of Management and Applied Science, 3(9), 39-43.

Ratna, R., \& Kaur, T. (2016). The impact of information technology on job related factors like health and safety, job satisfaction, performance, productivity, and work-life balance. Journal of Business \& Financial Affairs, 5(171), 2167-0234. 
Robinson, K. A., Saldanha, I. J., \& McKoy, N. A. (2011). Development of a framework to identify research gaps from systematic reviews. Journal of Clinical Epidemiology, 64(12), 1325-1330. doi:10.1016/j. jclinepi.2011.06.009

Schad, J., Lewis, M. W., Raisch, S., \& Smith, W. K. (2016). Paradox research in management science: Looking back to move forward. The Academy of Management Annals, 10(1), 5-64. doi:10.5465/19416520.2016.1162422

Schlachter, S., McDowall, A., Cropley, M., \& Inceoglu, I. (2018). Voluntary work-related technology use during non-work time: A narrative synthesis of empirical research and research agenda. International Journal of Management Reviews, 20(4), 825-846. doi:10.1111/ijmr.12165

Schmidt, F. L., \& Hunter, J. (2004). General mental ability in the world of work: Occupational attainment and job performance. Journal of Personality and Social Psychology, 86(1), 162-173. doi:10.1037/0022-3514.86.1.162

Smartphone Addiction. (2020). Smartphone addiction facts \& phone usage statistics: The definitive guide (20192020 Update). Retrieved from: https://www.bankmycell.com/blog/smartphone-addiction

Smith, W., Erez, M., Jarvenpaa, S., Lewis, M. W., \& Tracey, P. (2017). Adding complexity to theories of paradox, tensions, and dualities of innovation and change: Introduction to organization studies special issue on paradox, tensions, and dualities of innovation and change. Organization Studies, 38(3-4), 303-317. doi:10.1177/0170840617693560

Smith, W., \& Lewis, M. (2011). Toward a theory of paradox: A dynamic equilibrium model of organizing. Academy of Management Review, 36(2), 381-403. www.scopus.com

Smith, W. K., \& Tushman, M. L. (2005). Managing strategic contradictions: A top management model for managing innovation streams. Organization Science, 16(5), 522-536. doi:10.1287/orsc.1050.0134

Taylor, S., \& Todd, P. A. (1995). Understanding information technology usage: A test of competing models. Information Systems Research, 6(2), 144-176. doi:10.1287/isre.6.2.144

Ter Hoeven, C. L., van Zoonen, W., \& Fonner, K. L. (2016). The practical paradox of technology: The influence of communication technology use on employee burnout and engagement. Communication Monographs, 83(2), 239-263. doi:10.1080/03637751.2015.1133920

Tornatzky, L. G., Fleischer, M., \& Chakrabarti, A. K. (1990). The processes of technological innovation. Issues in organization and management series. Lexington Books.

Tran, Q. V., Le, P. H., \& Vo, T. Q. (2017). Quality assessment in systematic reviews: A literature review of health economic evaluation of hepatitis studies. Systematic Reviews in Pharmacy, 8(1), 52-61. doi:10.5530/srp.2017.1.10

Tranfield, D., Denyer, D., \& Smart, P. (2003). Towards a methodology for developing evidence-informed management knowledge by means of systematic review. British Journal of Management, 14(3), $207-222$. doi:10.1111/1467-8551.00375

van Zoonen, W., \& Rice, R. E. (2017). Paradoxical implications of personal social media use for work. New Technology, Work and Employment, 32(3), 228-246. doi:10.1111/ntwe.12098

Venkatesh, V., \& Bala, H. (2008). Technology acceptance model 3 and a research agenda on interventions. Decision Sciences, 39(2), 273-315. doi:10.1111/j.1540-5915.2008.00192.x

Venkatesh, V., \& Davis, F. D. (2000). A model of the antecedents of perceived ease of use: Development and test. Decision Sciences, 27(3), 451-481. doi:10.1111/j.1540-5915.1996.tb01822.x

Wei, C., \& Kolko, B. E. (2005, July). Studying mobile phone use in context: Cultural, political, and economic dimensions of mobile phone use. In IPCC 2005. Proceedings. International Professional Communication Conference, 2005 (pp. 205-212). IEEE.

Zhu, K., \& Kraemer, K. L. (2005). Post-adoption variations in usage and value of e-business by organizations: Cross-country evidence from the retail industry. Information Systems Research, 16(1), 61-84. doi:10.1287/ isre. 1050.0045

Zhu, K., Kraemer, K. L., Xu, S., \& Dedrick, J. (2004). Information technology payoff in E-business environments: An international perspective on value creation of E-business in the financial services industry. Journal of Management Information Systems, 21(1), 17-54. doi:10.1080/07421222.2004.11045797 
Zhuang, W., Hsu, M. K., Brewer, K. L., \& Xiao, Q. (2012). Paradoxes of social networking sites: An empirical analysis. Management Research Review, 36(1), 33-49. doi:10.1108/01409171311284576

Maria Alhadad is a PhD Scholar at Universiti Teknologi Malaysia, Jalan Sultan Yahya Petra, Kampung Datuk Keramat, Kualalumpur, Malaysia. Her area of interest in Technology Paradox and Human Resources Management.

Rosmini Omar is an Associate Professor at Azman Hashim International Business School, Universiti Teknologi Malaysia. She is also attached with University of Business and Technology, Saudi Arabia as an adjunct professor as well as a visiting instructor at Helsinki School of Business, Finland. Currently, she is a project coordinator for the grants-Erasmus+ Capacity Building for Higher Education: a) MSc. Food Processing and Innovation (http:// foodi-project.eu) and b) ASEAN Network for Green Entrepreneurship and Leadership (angel-project.eu). 